\title{
A descontinuidade da ruptura do sistema e reorientação pessoal
}

\author{
Alexander von Plato* \\ Tradução: Arthur Blásio Rambo \\ Revisão: Isabel Arend
}

\section{Nota introdutória: continuidade e ruptura depois de 1945 e depois de 1990}

Quero relatar algo sobre aquela parte do mundo, a Europa CentroOriental, distante do Brasil e, contudo, aproximando-se mais do que se poderia supor no que se refere à História Oral. Trata-se de uma região na qual, no decurso do século vinte, as populações foram obrigadas a lidar constantemente com rupturas nos sistemas ou se envolveram ativamente em fazê-las acontecer. Em praticamente todos os países da Europa Central e Oriental, na Alemanha, nos Estados do Báltico, na Polônia, na Tchecoslováquia, na Hungria e nos países dos Bálcãs - em toda a parte as populações foram obrigadas a assimilar, em apenas três gerações, cinco alternâncias dos sistemas políticos.

Também aqui na América do Sul e Central as populações se viram envolvidas em sucessivas rupturas políticas, ou na condição de integrantes das elites dos sistemas antigos, ou como ativistas dos novos, ou como vítimas de ambos, na condição de massa popular, massa de manobra dos diferentes sistemas, ou ainda como simples figurantes.

* Universidade de Hagen, Alemanha. 
A partir de análise historiográfica, verifica-se que a maior parte dos projetos de Historia Oral ocorreu nesta região do mundo, pois, a fonte oral mostra sua validade principal, nas entrevistas que envolvem histórias de vida, quando está em jogo:

- a repercussão de experiências históricas de longo prazo sobre os sistemas posteriores e sobre as novas orientações políticas;

- o envolvimento e a repercussão na sociedade da qual provêm, a penalização e a perseguição das antigas elites;

- a dinâmica que perpassa a vida dos indivíduos e dos grupos sociais;

- a recuperação da memória de um grupo e até de uma nação inteira, envolvendo sua memória cultural.

Aqui, na análise da história assimilada - e esta é uma das minhas suposições básicas - reside a sua principal força, menos na coleção de fatos e personagens, como na reconstrução de eventos e desfechos. Não obstante os estudos de História Oral realizados em Israel, EUA e Alemanha, na Europa Central e Oriental, tiveram papel fundamental na pesquisa que envolveu a "reconstrução fáctica" dos campos de concentração, a fuga e dispersão de milhões de pessoas nesta região, a perseguição de décadas da parte dos soviéticos a diversos grupos políticos e étnicos. Todas essas pesquisas têm por base, em primeiro lugar pelo menos, as fontes orais.

\section{A experiência da ruptura dos sistemas e sua pesquisa}

\section{A teoria de Bloch sobre a descontinuidade da ruptura sistêmica e reorientação pessoal}

$\mathrm{Na}$ análise da dinâmica temporal a descontinuidade, sobretudo em mudanças abruptas de sistema e morosidade da reorientação das pessoas, representa um sério problema de interpretação.

O filósofo alemão Ernst Bloch desenvolveu sua teoria da "descontinuidade" (Bloch, 1934) no começo do Nacional Socialismo. Para gerações representou uma importante categoria de análise do Nacional-Socialismo como também do período do pós Guerra na Alemanha. Na sua teoria muito mais complexa do que estou em condições de apresentar 
aqui, Bloch acredita que no presente age um passado não resolvido. Nele ocultam-se "esconderijos e sombras" por assim dizer incompatíveis com as novidades dos tempos atuais. Bloch fala de uma raiva represada e de um passado não resolvido, não apenas no sentido de um simples atraso, mas como de um futuro ainda não acontecido. "A raiva represada" pôde ser observada por nós em graus diferentes em toda a parte nas regiões de hegemonia soviética na Europa Centro-Oriental, não apenas contra o velho sistema, como também contra o novo que não inspira confiança e não está concluído. Acontece que a ruptura sistêmica não significa apenas libertação como também impedimento para a construção de um futuro planejado subjetivamente mas ainda não realizado. Trata-se de uma situação deveras ambivalente que desde o começo ameaça por em dúvida o Novo, tanto no plano genérico como concreto.

Todos esses elementos, a que Bloch se refere, têm um grande papel nas pesquisas que se relacionam com a ruptura de sistemas e reorientações. Libertação não é vista genericamente como libertação, mas também como perda ou ainda como empecilho da vida planejada, porém não concretizada. Isto aparece e, de modo especial, após as grandes rupturas dos sistemas na Europa Central e Oriental.

\section{A pesquisa biográfica quantitativa na Alemanha}

A pesquisa biográfica quantitativa teve, ao lado da qualitativa, significado fundamental na análise das conseqüências das rupturas nos sistemas políticos, principalmente examinando as histórias de vida das elites funcionais. ${ }^{1}$

Alguns exemplos: a mudança dos sistemas na Alemanha depois de 1945 e depois 1989/1990, atingiu de maneira bem diferente as várias classes de elite.

Primeiramente os professores. $\mathrm{Na}$ zona de ocupação soviética $88 \%$ dos professores e professoras foram substituídos até 1948. Os velhos docentes foram demitidos e instalados novos. Depois de 1990 aconteceu o mesmo nos novos estados federados com 18 a 25\% (Gruner, 1995). Contrariamente a 1945 a grande maioria pôde ficar.

1 O trabalho pioneiro na Alemanha foi de Wolgang Zapf (1965). 
Até policiais e integrantes do antigo funcionalismo da República Democrática da Alemanha (RDA, Alemanha Oriental) puderam, na sua maioria, permanecer nos seus postos. Sem dúvida foram despedidos todos aqueles que em 1989/1990 não renunciaram imediatamente a seus postos como membros ou colaboradores informais da segurança do Estado. Alguns tomaram essa decisão (também entre os colegas historiadores nas universidades e centros de memória). A maioria, contudo, abriu mão da vocação e procurou novas ocupações fora do serviço público antes de serem submetidos a uma investigação e serem colocadas a público suas antigas atividades junto a STASI. Apenas cerca de um por cento dos integrantes do serviço público nas diversos níveis do funcionalismo do Estado foi dispensado, baseado em exames realizados por funcionários encarregados dos arquivos da STASI (Plato, 1999).

Entre os empresários do oeste apenas de 8 a 15\% dos executivos mais altos ou dos representantes das organizações empresariais, respectivamente da indústria e das câmaras de comércio, foram substituídos depois de 1945. No leste estima-se que após 1945 esta cifra tenha chegado a $60 \%$ (Plato, 1993), dos quais a maioria tinha fugido para o oeste. De qualquer forma entre 30 a $40 \%$ dos membros menos graduados do partido filiados ao NSDAP (Partido Nazista) foram mantidos nos seus postos na indústria da RDA, porque foram indispensáveis para a reconstrução.

Depois de 1990 as perspectivas para a maioria dos "managers" dos conglomerados da RDA era ruim, menos por razões políticas do que por motivos econômicos. Essas empresas não tinham como subsistir na dura batalha da concorrência internacional e no mercado alemão. Só uma minoria dos seus diretores foi colocada como managers e outras firmas. Desativados os empreendimentos, a maioria ficou sem trabalho.

Depois de 1945 o jornalismo como profissão liberal ofereceu aos profissionais despedidos do serviço público, relativas oportunidades de construir uma nova existência não sujeita a controle. Quanto aos jornais do após guerra, sob a égide dos administradores das tropas de ocupação dos aliados, havia somente jornais novos que se mantêm até hoje no oeste. Os postos mais altos dos jornais como dos rádios foram substituídos, enquanto nos escalões inferiores das redações a maioria, isto é, $63 \%$, permaneceu nos seus postos, depois da fraca desnazificação no oeste. A maior porcentagem de continuidade aconteceu entre os jornalistas esportivos (Möding e Plato, 1989). 
A maior continuidade verificou-se entre o generalato do exército alemão criado em começos e meados de 1950. Presume-se que $90 \%$ do corpo de oficiais superiores integrara o exército durante a guerra. Também no leste o SED (Partido Socialista da Unidade, partido do Estado), ao estruturar o seu exército do povo, empenhou-se em reunir os oficiais e soldados egressos da Wehrmacht numa organização própria.

$\mathrm{O}$ último exemplo. O índice mais baixo de continuidade foi constatado entre as corporações de industriais e conselhos de produção. Uma análise dos conselhos de produção depois de 1945 na região do Ruhr mostrou que, apenas um único dos cerca de 5.000 candidatos nas eleições de 1946, já tinha sido conselheiro de confiança no tempo dos nazistas ele retirou sua candidatura. ${ }^{2}$

\section{História Oral como pesquisa de mentalidade}

Com certeza os senhores perguntarão: o que tem a pesquisa quantitativa de biografias a ver com a História Oral? Na verdade essas estatísticas só mostram alguma coisa sobre a continuidade ou descontinuidade nas profissões, nada, porém, sobre posturas e orientações pessoais ou coletivas dos integrantes daquelas elites. A esta altura somente a pesquisa histórica no nível da experiência, antes de mais nada a História Oral, é capaz de apresentar dados que, sem dúvida, podem ser confrontados com as pesquisas quantitativas.

Também para essa eventualidade quero trazer dois exemplos. A nossa pesquisa entre os empresários depois de 1945 mostrou que, mesmo entre os "managers" de ponta e os representantes das organizações de empreendedores, foram os nazistas que demonstraram posicionamentos diferentes, antes de mais nada na sua postura em relação às corporações. É licito até ousar a tese de que exatamente os "managers" oriundos do Terceiro Reich, os membros da NSDAP e os "Gefolgschaftsführer" (expressão nacional-socialista para diretores de empresas), mostraram esta atitude modificada. Estes, antes do que os empreendedores nacionalistas alemães sem compromisso da velha estirpe, que não tinham sido nazistas, mostraram-se prontos para uma colaboração corporativa num amplo

2 Veja minha pesquisa anterior (Plato, 1984). 
modelo de cogestão, para uma nova legislação para as empresas e um tal ou qual trabalho em comum com os dirigentes de sindicatos (Plato, 1993).

O segundo exemplo: as professoras e os professores da RDA logo de início mostraram-se como que entusiasmados quando se tratou de reorganizar as escolas da RDA ao modelo ocidental e a introdução do modelo didático ocidental, mas só por alguns anos. A lembrança das próprias experiências levou a crítica ao sistema escolar ocidental de três etapas e a volta à escola única (Einheitsschule) de 10 anos.

Bem diferente passaram-se as coisas num outro terreno, isto é, a aceitação de novos alimentos, bebidas, gostos, novos odores e modas. Quando entre 1990 e 1991 perguntei aos parceiros de entrevistas da antiga RDA se sentiam falta de algum tipo de bebidas, comidas ou artigos de lavanderia ou cabelo, encararam-me com um ar de compaixão. Eram muito poucos os que não tinham um "Broiler" (uma instalação especial para criar galetos), não dispunham de salsichas, os pequenos pães compactos, os pepinos em conserva ou a mostarda da RDA. Não demorou mais do que alguns anos e foram fundadas, primeiro alguns, depois sempre mais casas que vendiam com sucesso os velhos produtos da RDA. Os supermercados do oeste foram imitados pelo leste.

Hoje consegue-se comprar até cigarros ou espumantes em cujas etiquetas podem-se ler os antigos nomes, mas oferecendo produtos novos. O sabor mudou em grande parte, mas preservou-se o charme do nome antigo. Louva-se também o velho sistema de reciclagem ("Zero") da RDA, de modo especial creches e o velho sistema de saúde. Os então cidadãos da RDA usam "esses aspectos positivos" do antigo sistema, como escudos contra as criticas políticas dirigidas contra a ditadura da RDA e a violação dos direitos humanos. Esse fato levou também à autoconsciência da RDA.

Em junho de 1990 foi realizada uma pesquisa de opinião representativa na qual se perguntava se os entrevistados se sentiam mais como alemães do como antigos cidadãos da RDA. A maioria, $66 \%$ responderam considerar-se alemães. Só $28 \%$ consideravam-se de preferência como cidadãos da RDA (Noelle-Neumann, 1992).

Em junho de 1992, portanto três anos depois da virada, a situação era a oposta: $51 \%$ sentiam-se como cidadãos da antiga RDA e apenas $40 \%$ como alemães. 
Para explicar essa flagrante mudança não bastam os métodos convencionais de análise. Somente 25\% acreditavam, por exemplo, em 1992 que suas preocupações do quotidiano tinham aumentado, enquanto 75\% falavam de uma melhora. A simples explicação pela deterioração econômica também não basta. Em meados de 1992 a maioria falava numa melhora no plano econômico.

Ao mesmo tempo, em 1992, os antigos cidadãos da RDA sabiam mais sobre a STASI ${ }^{3}$ e a política do regime do SED, do que em 1990. A grande maioria não se declara nem contra a política do SED, nem dos seus representantes.

Mas há um amplo consenso entre as populações da antiga RDA - o que parece levar-me à trilha decisiva - que ninguém mais, em especial não alemães ocidentais, está em condições de julgar o tipo de vida e suas conseqüências na RDA, as mudanças e decisões, inclusive os envolvimentos políticos. Este consenso não aparece apenas nas pesquisas de opinião, mas transparece também nas muitas histórias que escutei no decorrer das entrevistas.

$\mathrm{Na}$ década de 1990 citava-se com freqüência a frase de um político do PDS - Partido da Democracia Social, o sucessor de então do SED partido do Estado: Tem-se a impressão que depois da virada a biografia pessoal foi desvalorizada. Hoje escuta-se além disto e, sempre com maior freqüência: "Nem tudo era ruim, no oeste também se cozinha apenas com água e coisas do gênero".

São apenas alguns flagrantes, contudo ajudam talvez a entender porque o PDS e agora "as esquerdas" obtiveram tanto êxito nas eleições no leste nos anos noventa. Agora a "esquerda" conta com resultados positivos também no oeste, de modo especial porque desde a política do chanceler Schröder, exatamente as classes mais baixas encontram-se em piores condições e a porcentagem dos pobres cresceu de $23 \%$ para $50 \%$, nos últimos dez anos. Também para uma parte da população do oeste, alternativas socialistas tornam-se de novo mais interessantes.

3 Abreviação para Segurança do Estado, assim como Ministério de Segurança do Estado (MfS), a Polícia Secreta da RDA. 


\section{Observação sobre a História Oral na Europa Centro-Oriental}

O notável é o seguinte. Quando se examina a evolução do estudo de biografias e a história oral na Europa Oriental, constata-se que lá não há (quase não há) pesquisas sobre as continuidades e rupturas entre as elites ou no posicionamento de certos grupos da população. Trabalha-se, antes de tudo, com a experiência vivida sob a ocupação pelo exército alemão ou do holocausto de 1945, portanto, sobre a segunda guerra mundial. A experiência com a ocupação União Soviética e o "Socialismo Real", pelo contrário, merece um papel secundário. Numericamente ainda menos importantes são as pesquisas envolvendo a experiência das rupturas como também a posição da população ou das elites sob o socialismo depois de 1990.

A Gesellschaft Memorial, uma ONG do oeste, apresentou alguns trabalhos sobre as vitimas na União Soviética. Os questionamentos sobre a ocupação soviética da Europa Centro-Oriental são objetos de tematização essencialmente na Polônia, (patrocinada pela Fundação KARTA em Varsóvia ou pelo Instituto Nacional de Memória - IPN). Trata-se, portanto de instituições não universitárias, ou de exposições e museus na Polônia, na Hungria e nos países do Báltico. Algumas vezes o período da ocupação e hegemonia soviética é relativizado comparando-o com os crimes do Nacional Socialismo sob a ocupação alemã. Em contrapartida as rupturas e continuidades de contingentes maiores da população em todos esses países, depois de 1990, praticamente não contam com pesquisas. ${ }^{4}$ Nesse sentido o impulso experimentado pela história oral atualmente nesta região (como se verá abaixo) precisa ser encarado com alguma reserva.

Antes de me ocupar com esse relativo impulso, quero abordar alguns problemas específicos, enfrentados pela pesquisa biográfica e a história oral na Europa Centro-Oriental.

4 Sobre a Bulgária existe o trabalho de Daniela Koleva (2001). Na República Tcheca inicia-se atualmente uma análise com História Oral sobre a vida no socialismo no Instituto de História Contemporânea. 


\section{Os problemas do desenvolvimento da História oral na Europa Centro-Oriental}

Seguem alguns problemas no plano da história da ciência e da história da ciência política, especialmente importantes para desenvolver a história oral e a pesquisa das histórias de vida na Europa Oriental.

O primeiro problema: até 1990 não havia uma tradição na formação para tais estudos qualitativos na Europa Oriental sob a influência soviética. Em alguns países desenvolveram-se estudos consistentes do folclore e da etnologia, assim, por exemplo, a partir de Moscou na Sibéria e na Bulgária sobre ciganos. Acontece que neste período essa linha de pesquisa é tida como "subjetivista" e rejeitada nos espaços de hegemonia soviética, pois predominava a opinião de que a experiência histórica dos sujeitos nem sempre estava em sintonia com o ponto de vista do partido que estava no poder. Procurei mostrar como na Alemanha, assim como em todos os países com freqüentes alternâncias de sistema e pontos de vista diferentes em relação "às políticas do passado", em questão de poucas gerações abre-se um amplo espaço e tarefas para a História Oral.

O segundo grande problema: sabemos todos com que força a cultura da memória, a ascendência/origem e suas narrativas dominantes, apagam a comunicação, influenciam a elaboração da história dos informantes; o quanto a narrativa de outros ou os documentos são capazes de modificar a memória de testemunhas da época. Isto ocorreu obviamente também na Europa Oriental. Neste caso encontrava-se presente uma forte "pressão para unificação" das narrativas por um modelo de narrativa padrão soviético, durante a segunda guerra mundial. O elemento consensual nos países da antiga União Soviética foi a vitória sobre a Alemanha na "Grande Guerra Patriótica". Durante décadas vigorou a "política do passado"5 imposta pelo Estado. Nela destacava-se o papel do exército vermelho, dos guerrilheiros comunistas e da liderança da KPdSU, os partidos simpatizantes. Por mais compreensível que seja essa atitude depois da vitória sobre um agressor, tido como super poderoso, tanto mais elementos menos heróicos da guerra foram ignorados: antes de mais nada a

5 Este conceito de Norbert Frei parece-me mais adequado para designar a vinculação de Política e História. Cf. Norbert Frei, 1996. 
dominação ditatorial, as enormes baixas de soldados do exército vermelho, ou os crimes cometidos durante a ofensiva sobre outros países, principalmente da Europa Oriental. Sob a idéia da luta heróica o extermínio dos judeus europeus foi subsumido e os sofrimentos dos prisioneiros de guerra soviéticos ${ }^{6}$ foram menosprezados como foi o caso dos trabalhadores e trabalhadoras forçados, se é que não foram tratados como traidores em potencial. ${ }^{7}$ Depois de 1990 surgiram na Polônia e em outros países da Europa Oriental tendências crescentes empenhadas em trabalhar seriamente a própria história, inclusive do período do domínio soviético. Essa tendência contrapôs-se vigorosamente à até então maneira oficial de escrever a história.

Essas contradições podiam ser constatadas entre a memória coletiva dos comunistas e guerrilheiros de um lado e as ilhas de uma outra cultura de memória, isto é, da não oficial, as vivências e reminiscências próprias, da tradição familiar, a tradição de grupos menores de prisioneiros de guerra e trabalhadores e trabalhadoras forçadas.

O terceiro grande problema. Depois de um breve período de liberdade nos anos noventa, também da ciência e da pesquisa, o governo russo mudou a lei liberal dos arquivos de 1993: tudo que tinha relação com o exército vermelho, o serviço secreto, a polícia política (também dos países ocupados pela União Soviética), foi interditado. Tudo o que era antipatriótico era criticado, difamado e colocado de escanteio.

Nos diversos países sob a antiga influência soviética, podiam-se perceber, depois de 1990, formas divergentes de lidar com o passado stalinista e do nacional-socialismo. $\mathrm{Na}$ Alemanha Oriental, todos os membros da SED ou segurança do Estado, foram mantidos longe do serviço público. Foi criada uma repartição específica encarregada de arquivar os documentos da segurança do Estado. Quem tinha sido "superior burocrático" ou "colaborador informal" da segurança do Estado, tinha permissão de permanecer no serviço do Estado, sob a condição de ele ou ela o tornar logo público. Escolas ou instituições públicas podiam informar-se

6 Para um estudo dos prisioneiros de guerra soviéticos confira o trabalho pioneiro de Christina Streit (1978). Para os trabalhos forçados: Ulrich Herbert, 1985; Mark Spoerer, 2002. Sobre o debate sobre indenizações, cf. Lutz Niethammer, 2007.

7 Para a Rússia e pela Rússia confira os trabalhos de Pavel Poljan, 1953. Confira ainda Christian Gerlach, 1999; Alexander von Plato, Almut Leh e Christoph Thonfeld, 2008. 
com esses funcionários, se uma determinada pessoa tinha pertencido à STASI. E apenas em torno de 1\% foi excluído do serviço do Estado depois do pedido de informações junto a tais funcionários. O mais importante, contudo, foi que as vítimas do antigo sistema puderam verificar o que constava sobre eles nos registros da STASI. Na maioria dos países da Europa Oriental foi diferente. Na Polônia, os registros deveriam ficar fechados para não abrir simplesmente a porta para a denúncia pública generalizada. Entretanto, esses registros sobre determinadas pessoas circulavam nos meios de comunicação de massa. O caso mais conhecido foi o do bispo que trabalhara para a polícia política local. Na Rússia, esse tipo de registro simplesmente não foi liberado. Poderia multiplicar os exemplos. Em resumo, afirma-se que o povo foi informado de diferentes formas sobre o sistema passado, o que levou à formação de diversas maneiras de julgar esse passado.

Tudo isso, especialmente o último problema apontado, exerceu uma influência negativa sobre a evolução dos projetos de História Oral, que tinham como objeto a história do stalinismo, as vítimas, os custos da guerra, inclusive os crimes envolvendo o exército vermelho no seu avanço.

\section{Impulso relativo da pesquisa biográfica e da História Oral}

Quando se analisam as dificuldades enfrentadas pela pesquisa biográfica na Europa Centro-Oriental, é preciso ter em alta consideração as linhas de pesquisa nessa direção. Na primeira década depois da grande mudança entre 1989 e 1990, verificou-se um impulso limitado nas pesquisas à base de fontes orais ou entrevistas sobre histórias de vida. Algumas amostras para esclarecimento.

Em Praga formou-se uma nova associação de História Oral, no âmbito do Instituto para História Contemporânea (Zeitgeschichte). Exatamente neste momento foi posto em andamento um grande projeto de entrevistas sob o título: "Nós vivemos no Socialismo". Nele pergunta-se às pessoas, sem qualquer restrição e sem qualquer preconceito, sobre suas vivências na CSSR.

Também existe uma Nova União de História Oral em Charkiw no leste da Ucrânia. Durante uma série de anos tenta-se aí perguntar a representantes de diferentes grupos da população a respeito das experiências sob a ocupação pelo exército alemão durante a guerra. Também no oeste 
da Ucrânia há tentativas para analisar a história das vítimas do stalinismo, com o auxílio da História Oral e estudos de biografia. O papel pioneiro cabe neste caso, de modo especial, à universidade católica de L'wiw (L'wow ou Lemberg). Ela ofereceu também o espaço para a realização da primeira conferência internacional de História Oral, organizada por Viktor Susak em 1994 e foi de grande importância para o estabelecimento de contatos entre os historiadores orais da Europa Oriental e Ocidental. Praticamente todos que se ocupam hoje com o tema estiveram presentes.

Uma evolução semelhante, porém mais fraca, aconteceu nos Estados do Báltico. Em Riga foram realizadas algumas conferências, nas quais foram apresentados os resultados de projetos de História Oral. Na Estônia trabalham alguns historiadores, principalmente historiadoras que publicaram trabalhos de História Oral, relativos ao tempo do Nacional Socialismo e do Stalinismo. Conjuntamente foram tratadas as deportações das elites do Báltico para a União Soviética.

$\mathrm{Na}$ Hungria foram realizadas entrevistas orais ainda durante o antigo regime. Mais conhecido tornou-se o Instituto para o Estudo da Revolução de 1956, ao qual encontra-se anexo um arquivo de História Oral, fundado por Andras B. Hegedus. Andras foi escolhido para integrar o Comitê Internacional de História Oral. Infelizmente faleceu neste meio tempo.

Na Polônia existem há anos iniciativas de pesquisa, nas quais se realizam também entrevistas orais, tanto pela fundação KARTA como pelo Instituto Nacional da Memória (IPM), quanto em institutos universitários isolados. Neste contexto é preciso citar a Casa Willy Brandt em Wroclav/ Breslau que há anos promove estudos sobre a memória do tempo da guerra e do pós-guerra. Recentemente o então diretor, Kristoff Ruchniewicz apresentou um trabalho que recorda Katyn (onde em 1940 milhares de integrantes da elite polonesa foram executados por pelotões de fuzilamento soviéticos).

Na Bulgária também existem há anos trabalhos de História Oral, voltados principalmente para as diferenças entre a memória oficial e privada, para determinados grupos étnicos, antes de mais nada os ciganos. Uma representante dessa linha de História Oral, Daniele Kholeva, foi durante anos, junto com Nancy Adler (Cf. Adler, 2001), diretora do departamento de História Oral da European Social History Conference. 
Principal sede de um Seminário Internacional de História Oral foi o Instituto Etnológico de Sofia e o museu anexo. A conferência era financiada pelo Instituto Goethe.

Em meio a enormes dificuldades foram feitas algumas tentativas até na Rússia Branca (Bielorússia), no sentido de trabalhar alguns temas com o auxílio do método da entrevista. Entre elas, por exemplo, trabalhos sobre o Gueto em Minsk, sobre a sorte de mulheres na guerra ou sobre trabalhadores e trabalhadoras forçadas.

E agora sobre a então Europa Centro-Oriental: em condições quase clandestinas foi realizada em 1989 em Moscou a primeira Conferência Internacional promovida pela Universidade de Ciências Humanas. O então diretor Jurij Afanasjew, conselheiro de Gorbatschow, tomou sobre si o patrocínio da Conferência. Ao lado de muitos historiadores orais fizeram-se presentes colegas oriundos das repúblicas soviéticas como a Geórgia, Armênia, Azerbaijão, dos estados do Báltico, da Ucrânia e obviamente da Rússia. Na União Soviética sobreviveu oficialmente a pesquisa qualitativa baseada em entrevistas orais, de modo especial na Etnologia. Com a evolução da Perestroika o interesse pela História do Quotidiano e pela História Oral teve penetração, pelo menos por pouco tempo, nos Institutos Históricos. De modo especial no Instituto para a História e Arquivística de Moscou, sob a coordenação de Jurij Afanasjew, consolidaram-se vários projetos que têm como propósito estudar a história do Stalinismo tendo como viés a história das vítimas da resistência. Também na Província, nas repúblicas com fortes movimentações nacionalistas, como na Geórgia e no Báltico, a História Oral viveu um período de alta. A maioria dessas iniciativas enfrentou, sem tardar, problemas diversos, aos quais me referi mais acima. A "Sociedade Memorial" que na década de 1980 foi criada por opositores, entre eles Sacharow e, em 1989, mantinha relações estreitas com esses projetos nas repúblicas soviéticas, ainda hoje é o centro com suas sedes em Moscou e St. Petersburgo. Realizou uma quantidade de entrevistas, organizou Círculos Sociais para as vítimas do Nacional Socialismo e do Stalinismo. Editou uma série de publicações, entre elas as condições na União Soviética no tempo de Stalin.

Não se pode ignorar que também fora dessas capitais, como em Woronesch, surgiu um centro de História Oral, que realizou semestres de verão (dos quais participamos Almut Leh e eu). Hoje passam por grandes dificuldades. 
$\mathrm{Na}$ Europa Ocidental aconteceram várias Conferências Internacionais com temas de História Oral, relacionadas com a pesquisa qualitativa na Europa Oriental. A VII Conferência de História Oral realizada em Essen em 1990, deu ênfase especial à História Oral na União Soviética. As palestras essenciais foram por mim publicadas em $1990 \mathrm{em}$ BIOS. Em 2005 o Instituto para História e Biografia em parceira com o "Berliner Stiftung Aufarbeitung", promoveu uma grande Conferência sobre História Oral na Europa Oriental. Infelizmente foram publicados apenas os resumos. Em 2006, Freiburg/Br foi a sede da Conferência de História Oral na Europa Oriental de longe a mais abrangente. Na Inglaterra, Rob Perks promoveu repetidas Conferências relativas à Ucrânia, seguidas da publicação dos resultados.

Três grandes projetos internacionais de História Oral, realizados fora da Europa Oriental, foram levados a efeito na Europa Oriental. Envolveram entrevistas de massa com sobreviventes do Holocausto realizadas pela Fundação Spielberg em quase todos os países da Europa Oriental. O outro projeto envolveu entrevistas com antigos prisioneiros do Nacional Socialismo no campo de concentração de Mauthausen. Foram realizadas na Áustria e coordenadas pelo colega de Viena, Gerhard Botz. Foram feitas 840 entrevistas em 25 países. O terceiro projeto teve como alvo escravos e trabalhadores e trabalhadoras forçadas, coordenado por mim em parceria com Almut Leh e Christoph Thonfeld na Universidade de Hagen. Cerca de 600 entrevistas foram efetuadas em 27 países. Todos esses projetos contaram com a colaboração de colegas de muitos países, que fizeram as entrevistas "in loco" e na língua do local. Aconteceram três seminários no contexto do projeto dos trabalhadores forçados, com a finalidade de afinar a todos no mesmo nível na condução das entrevistas. O livro sobre os trabalhadores forçados deve ser publicado dentro de quatro semanas. Como sinal do bom resultado dessa tarefa é o fato de que, depois da Conferência Internacional de História Oral em Guadalajara, a seguinte terá lugar em Praga, na República Tcheca.

Depois desses resultados positivos, perguntas fundamentais da pesquisa sobre rupturas de sistemas, embora sejam interrogações clássicas da História Oral, não foram trabalhadas na Europa Oriental. Entre elas a grande pergunta: o que permanece do velho sistema na memória dos diversos grupos de populações e por quê? Segundo: que tipos de continuidades e que rupturas nas profissões se percebem nas diversas elites? 
Terceiro: ocorreram fases intermediárias, nas quais os novos sistemas foram aceitos pela maioria da população e, depois, novamente rejeitados? Em caso afirmativo, por quê?

Quem sabe essas questões serão tratadas na próxima Conferência Internacional, da qual, presume-se, participem bem mais colegas europeus orientais do que até agora, pois acontece em Praga não tão distante. Essas Conferências funcionaram sempre como catalisadoras para a História Oral naquelas regiões.

\section{Europa Oriental - uma colcha de retalhos de Culturas de Memória}

$\mathrm{Na}$ terceira parte da minha conferência quero falar sobre as várias culturas de memória que formam uma colcha de retalhos na Europa Oriental e sobre as tendências na, teoria, de acentuar o desenvolvimento de memórias coletivas nacionais, enquanto que a base de muitos estudos de História Oral seja antes a ênfase na multiplicidade e na clivagem das memórias, não apenas na Alemanha, mas também nos países da Europa Oriental.

No Congresso Internacional, envolvendo o trabalho forçado em 27 países, é possível constatar que nos países da Europa Oriental ocorre uma espantosa internacionalização da História do Holocausto e, ao mesmo tempo, uma evidente nacionalização da História do Trabalho Forçado, de modo especial em mostras de museus e entre as pessoas envolvidas.

Depois da guerra predominou na Europa Oriental o discurso soviético da Grande Guerra Patriótica e os heróicos combatentes, soldados e partidos comunistas. Já chamei a atenção que coisas menos heróicas foram varridas para debaixo do tapete. Sob a influência soviética na Europa Oriental não pertenceram apenas estados que, durante a guerra estiveram aliados à União Soviética contra o Reich alemão, como também aqueles que antes haviam lutado ao lado do Reich alemão contra a União Soviética, como a Bulgária, a Eslováquia, a Croácia e outros. ${ }^{8}$

8 Confira entre outros: Ana Luleva sobre a Bulgária, Viola Jakschowá sobre a Eslováquia, e Christian Schölzel sobre a Croácia (in Plato, Leh e Thonfeld. 2008). 
O espantoso é que também nesses países se impôs a imagem heróica do exército russo e do partido comunista que por décadas ditou as políticas históricas. O êxito desse discurso comunista na Croácia e na Bulgária, como também na Eslováquia ocupada e dividida, em minha opinião, não se explica apenas que aí, depois de 1945, os partidos que tinham sido aliados da União Soviética ocuparam o poder, como pelo fato de, depois de uma curta, mas muito dura fase de repressões, instalou-se uma anistia não oficial e tácita, em relação aos antigos adversários, promovida pela ideologia e práxis do Estado. Isto significa que também os antigos inimigos vivem nesses estados e até fazem carreira dentro de certos limites, quando não se manifestam ou defendem abertamente outra forma de encarar a história. É exatamente o quadro histórico dominante dos heróicos soldados soviéticos e guerrilheiros comunistas, que permitiu a tranqüilidade interna desses antigos estados da União Soviética, pelo menos por um tempo limitado de uma ou duas gerações. Situação semelhante verificou-se na França onde por décadas não se falou na colaboração com a Alemanha nacional socialista.

$\mathrm{Na}$ memória cultural ou mais exatamente, nas memórias culturais dos diversos países da Europa Oriental e Ocidental, da América ou Israel, assim como nos países de imigração, os prisioneiros de guerra ou os trabalhadores e trabalhadoras forçadas desempenharam um papel muito diversificado. De acordo com as oportunidades de articulação que lhes foram dadas, tipo de reconhecimento ou rejeição que experimentaram ou até que ponto suas experiências se misturaram com as dos outros ou por elas foram dominadas, o peso a elas dado, variaram na memória dos testemunhas da época e nos seus julgamentos posteriores sobre os trabalhos forçados sob o Nacional Socialismo. ${ }^{9}$ Tais histórias dominantes que se intrometeram são, por ex., aquelas dos Shoah ou vitória heróica da União Soviética durante a grande guerra.

O governo soviético sob Stalin negou qualquer reconhecimento aos trabalhadores e trabalhadoras forçadas. Quase todos passaram na sua volta para casa pelos assim chamados acampamentos de triagem, para detectar uma possível colaboração com a Alemanha, mas depois de pouco tempo

9 Confira em primeiro lugar os trabalhos de Irina Scherbakowa (Memorial Moskau) e Anna Reznikowa (Memorial St. Petersburg) ou também de Alexander Dalhouski (Weissrusland) (in: Plato, Leh e Thonfeld, 2008). 
foram liberados. Outros foram obrigados a continuar executando trabalhos forçados e só mais tarde tiveram permissão para voltar para casa, outros ainda forçados a servir no exército vermelho, muitas vezes por anos, e os últimos, confinados em acampamentos penais. Sergej Mironenko, diretor do Arquivo do Estado da Federação Russa em Moscou, estima que não mais do que $10 \%$ dos trabalhadores e trabalhadoras forçadas que voltaram para casa tiveram que passar mais de três meses nos acampamentos de triagem. Com certeza o número foi maior dos que estiveram no exército vermelho ou dos enviados para trabalhos longe de casa. ${ }^{10}$ Mas a maioria percebeu, com grande preocupação e decepção, logo depois da chegada em casa que, de antemão, eram suspeitos de colaboração ou traição.

Mas também os países da Europa Central e Oriental que reconheceram os trabalhadores forçados ou, pelo menos, não os colocavam sob suspeita de colaboradores, os marginalizaram na memória coletiva. Predominaram os cultos aos combatentes e guerrilheiros comunistas.

Ao contrário da União Soviética, os prisioneiros de guerra poloneses, como os trabalhadores e trabalhadoras forçadas, não foram tratados como possíveis traidores ou colaboradores. ${ }^{11}$ De maneira parecida foi na Tchecoslováquia (e com ela também na recém extinta república da Eslováquia, ${ }^{12}$ então aliada dos alemães). Uma parte dos trabalhadores e trabalhadoras forçadas na Iugoslávia foi, sob alguns aspectos, equiparada aos guerrilheiros. $\mathrm{Na}$ Eslovênia, contudo a situação depois da guerra foi diferente. No processo sobre Dachau levado a efeito aí, trabalhadores e trabalhadoras forçadas, recém libertados, foram condenados como colaboradores ou criminosos. ${ }^{13}$ De mais a mais reina na Iugoslávia socialista o orgulho por terem vencido a Alemanha nacional-socialista, o que incluía os trabalhadores e trabalhadoras forçadas, enquanto na União Soviética manifestava-se orgulho pelos soldados que se posicionaram contra o

10 Especialmente em conversas com o autor.

11 Confira para o geral sobre a volta para casa de escravos e trabalhadores forçados a contribuição de Christof Thonfeld assim como o relato de Piotr Filipkowsdi (KARTA) sobre a Polônia.

12 Veja os artigos de Sárka Jarská (República Tcheca) e Viola Jakschowa (Eslováquia), in Plato, Leh, e Thonfeld, 2008.

13 Veja mais de modo especial os artigos de Monika Kocevar sobre a Eslovênia, de Christian Schoelzel sobre a Croácia e Bárbara Wiesinger sobre a Sibéria. 
reconhecimento dos prisioneiros de guerra, os trabalhadores e trabalhadoras forçadas como perseguidos do Nacional-Socialismo.

Não só na Europa Oriental impôs-se, nas primeiras décadas depois da guerra, uma imagem da história da Segunda Guerra Mundial, imposta pela guerra heróica contra o Reich Alemão Nacional-Socialista e a resistência contra o Fascismo. Também na maioria dos países da Europa Ocidental predominavam maneiras de ver semelhantes, às quais subordinavam-se alguns aspectos menos heróicos. Na França, por exemplo, a cultura da memória foi marcada pelo papel do governo no exílio de De Gaule e pela Résistance. A grande massa dos franceses, entretanto, teve que se haver com a ocupação alemã ou a França de Vichy, do marechal Petain, e uma minoria deles na resistência. Mas colaboração, composição e oportunismo são pouco adequados para a construção de uma identidade nacional. ${ }^{14}$

Muito mais difícil ainda foi integrar neste quadro os cúmplices e colaboradores na eliminação dos judeus franceses. Também aqui ajudou, direta ou indiretamente, àqueles que colaboraram com ocupação alemã, àqueles que cometeram crimes contra a humanidade ou se acomodaram à situação, o discurso predominante sobre a Résistance e do governo no exílio. Só mais tarde, depois de algumas entrevistas mais antigas sobre o período imediatamente após a guerra, aconteceu uma discussão com colaboradores na França. Mas mesmo até hoje, fazem-se distinções, por exemplo, entre os trabalhadores e trabalhadoras forçadas que foram transportados da França ocupada para a Alemanha e aqueles que foram levados para a Alemanha com documentação francesa da França de Vichy. Os primeiros foram tratados como vítimas do nazismo e tratados como resistentes, os outros não.

Semelhantes contradições verificaram-se em outros países da Europa Ocidental, como por exemplo, na Dinamarca, onde houve alianças com a Alemanha nazista, na Noruega onde se originou o conceito de governo de colaboração, sob o governo colaboracionista forçado sob Quisling, como também na Bélgica. A Itália merece destaque especial. No pós-guerra acentuou-se a derrocada do fascismo de Mussolini, embora a resistência tivesse sido pouco desenvolvida e o rei Vittorio Emanuele III

14 Confira a contribuição de Anne-Marie Granet-Abisset em Plato, Leh e Thonfeld 2008, e também o seu estudo "Temoins et temoignages em situation limite" (1999) 
e o novo governo tivessem que fugir em seguida. Verdadeiro heroísmo mostrou o grosso dos soldados italianos, que não se colocaram do lado do exército alemão, oferta quase em toda a parte feita pelos militares alemães. Escolheram o cativeiro e como "militares italianos internados" foram obrigados a trabalhos forçados na Alemanha e nos países ocupados. Sua história, porém, foi marginalizada em função da história da resistência, da deposição de Mussolini e da declaração de guerra à Alemanha (Sommaruga, 2004).

Somente em tempos mais recentes, anos após a morte de Franco e a passagem para a democracia sob uma monarquia constitucional, começou-se na Espanha a trabalhar a história do Regime de Franco e suas vítimas e a examinar a história das vítimas da guerra civil e da ditadura. A assim chamada "Lei da Memória", votada no parlamento espanhol em 12 de dezembro de 2006, deverá mudar essa situação.

A Áustria normalmente é esquecida nesse contexto, embora de cada dez homens e mulheres, um ou uma, tivesse sido levado para a Alemanha para executar trabalhos forçados, em números absolutos, no mínimo um milhão de pessoas (ver Perz, 2007). O campo de concentração de Mauthausen, com seus campos anexos e a mal afamada pedreira, foi um dos mais terríveis campos de concentração para trabalhos escravos. Além disto, havia organizações de perseguição formadas por elementos austríacos da SS, entre eles a direção dos programas de eutanásia dos “T4". ${ }^{15}$ Há décadas a Áustria pôde esconder-se atrás da política começada pelos aliados em Moscou, que o país foi a primeira vítima da expansão nacionalsocialista. Somente uma controvérsia nos anos 1986-1987, envolvendo o passado do Secretário Geral da ONU (1976-1981) e presidente da República 1986-1992) Kurt Waldheim, levou a uma avaliação diferenciada.

Durante anos, na própria Alemanha, os antigos desertores condenados, os presos políticos, que foram obrigados freqüentemente a trabalhos forçados, os escravos e trabalhadores e trabalhadoras forçadas, não foram reconhecidos e em massa tiveram que batalhar em vão, durante muito tempo, por indenizações. Demorou quase uma geração até que se começassem mudanças, e duas gerações para que politicamente fossem reconhecidas as indenizações.

15 A condução do programa nacional-socialista da eutanásia era feita por membros austríacos da SS com posições decisórias e tinha sua sede na Tiergartenstrasse 4 em Berlin (por isso "T4") 
Pelo contrário havia um alto reconhecimento pelas vítimas do nacional socialismo em Israel, EUA e, de maneira mais limitada, em países de imigração, valendo-se de formas próprias de organização e políticas de memória.

Em resumo, queremos afirmar: tomando como referência a memória da Segunda Guerra Mundial, a Europa parece ainda hoje uma grande colcha de retalhos considerando a memória da Guerra, do Holocausto, da Resistência, dos Prisioneiros de Guerra, assim como dos Trabalhadores e Trabalhadoras Forçadas. Ainda se ouvem os ecos das antigas posições do tempo da guerra. Os diversos sistemas políticos sustentam memórias coletivas consolidadas em diferentes espaços regionais, impulsionadas pela Guerra Fria e valendo-se da história e da memória da guerra. As "culturas de memória" na Europa Ocidental são também muito mais fragmentadas, como sugerem as "políticas históricas" do pós-guerra. O discurso predominante da guerra anti-fascista e da resistência foi, para repeti-lo de novo, muito exitoso exatamente porque mascarava as páginas menos heróicas da guerra, a colaboração e participação em crimes e, desta maneira, permitiu às sociedades do pós-guerra pelo menos uma reconciliação superficial. Mas em meio a essas políticas históricas permaneceram ocultas outras informais, principalmente, culturas de memória familiares que entraram em atrito com as oficiais, principalmente na Europa Oriental, mas não somente lá. Não fica claro, porém, que tipo de "pactos de memória" são firmados pelas novas gerações na Europa unificada politicamente, agora no começo do século 21.

\section{Referências bibliográficas}

ADLER, Nancy. Die Erinnerungen an die komunistische Machtübernahme in Bulgarin am 9 September 1944, in BIOS, Jg. 14, Heft 1, S. 102 ff, 2001.

BLOCH, Ernst. Erbschaft dieser Zeit. Zürich, 1934.

FREI, Norbert. Vergangenheistspolitik. Die Anfänge de Bundesrepublik und die NS Vergangenheit. München, 1996.

GERLACH, Christian. Kalkulierte Morde. Hamburg, 1999.

GRANET-ABISSET, Anne-Marie. "Temoins et temoignages em situation limite”. In: Wievioka, A.; Mouchant, C (Hg.): La Shoa, oeuvres et témoignages, 1999, S. 189-202. 
GRUNER, Petra. “Nun dachte ich, jetzt fingt's neu an, nun soll'sozial werden...” Zur Kritik des Neulehrermythos. In: Zeitschrift für Pädagogik, 41, Jg. 1995 (Nr. 6), S. 943-957

HAMMERMANN, Gabrielle. Gli internati militari italiani in Germânia, 1943-1945, trad. It. Il Molino, Bologna, 2004.

HERBERT, Ulrich. Fremdarbeiter. Politik und Praxis des “Ausländer Einsatzes" in der Kriegswirtschaft des Dritten Reiches. Berlin/Bonn, 1985.

KARNER, Stefan; RUGGENTHALER, Peter; STLEZ-MARX, Barbara. NS-Zwangsarbeit in der Rüstungsindustrie. Die Lapp-Finze AG in Kalsdorf bei Graz, Graz 2004 S.8.

KOLEVA, Daniela. "Die Erinnerung an die kommunistische Machtübernahme in Bulgarien am 9. September 1944” BIOS 2001, p. 101 ss.

MÖDING, Nori; PLATO Alexander V. (unter Mittarbeit von Alice Petersen, 1989) Nachkriegspublizisten. Eine erfahrungsgeschichtliche Untersuchung. In Peter \& Erika M. Hoerning (Hrsg.) Biografisches Wissen. Beiträge zu einer Theorie lebensgeschichtlicher Erfahrung, Frankfurt a. M. 1989, S. 38-69.

NIETHAMMER, Lutz. Von der Zwangsarbeit im Dritten Reich zur Stifftung "Errinerung, Verantwortung und Zukunft". In: “Gemeinsame Verantwortung und moralische Pflicht”. Abschlussbericht zu den Anzahlungsprogrammen der Stiftung "Erinnerungeh, Verantwortung und Zukunft", hg. von Michael Jansen und Günter Saathoff, Göttingen, 2007, S. 13-84.

NOELLE-NEUMANN, Elisabeth. Ausarbeitung der Vergangenheit im Schatten der Stasi. Selbstgespräch und Wir-Gefühl in den neuen Bundesländer, in: FAZ v. 12.8.92, S. 8.

PERZ, Bertrand. Holocaust Studies Tagung "Arbeit und Vernichtung” der Arbeiterkammer in Wien vom 27, bis 29 Juli 2007 in seiner Einführung a 27. Juli, a.a.O.

von PLATO, Alexander. "Entstatizierung” im Öffentenlichen Dienst der neuen Bundesländer nach 1989. Umorientierung und Kontinuität in der Lehrerschaft. In: Jabrbuch für Historische Bildungsforschung, Band 5, Bad Heilbrunn/Obb. 1999, S. 313-342

"Wirtschaftskapitäne" Biographische Selbskronstruktion von Unternehmern der Nachkriegszeit, in: Schild, Axel und Arnol Sywottek (Hg.): Modernisierung im Wiederaufbau. Die westdeutsche Gesellschaft der 50er Jahre, Bonn 1993, S. 377-391

“Der Verlierer geht nicht leer aus”. Betriebsräte geben zu Protokoll. Berlin/Bonn 1984

von PLATO, Alexander; LEH, Almut. "Ein unglaublicher Frühling” Erfahrungsgeschichte in Deutschland 1945 bis 1948, (Bundeszentrale für politische Bildung). Bonn, 1998, S. 89 ff.

von PLATO, Alexander; LEH, Almut; THONFELD, Christoph (Hg.). Hitlers Skalven. Lebensgeschichtliche Analysen zur Zwangsarbeit im internationalen Vergleich, Wien, 2008.

POLJAN, Pavel. Die Erinnerungen an die Deportationen während der deutschen Besatzung in der Sowjetunion. In: Hans Christoph Seidel und Klaus Tenfelde (Hg.); Zwangsarbeit in Europa des 20. Jahrhunderts. Bewältigung im Donbass unter stalinistischer und 
nacionalsozialistischer Herrschaft, 1929 bis 1953, S. 227-252.

SOMMARUGA, Cláudio. Cifre della resistenza degli ufficiali italiani nei lager nazisti. In:

"Quaderni di storia contemporânea", VI (1986), S. 21-38.

SPOERER, Mark. Zwangsarbeiter unter dem Hakenkreuz. Stutgart/München, 2002.

STREIT, Christina. Keine Kameraden. Die Wehrmacht und die Sowjetischen Kriegsgefangenen 1941-1945. Stuttgart, 1978

ZAPF, Wolgang. Wandlungen der deutschen Elite. Ein Zirkulationsmodell deutscher Führungsgruppen 1919 bis 1961, München 1965.

Resumo: Neste artigo pretende-se efetuar algumas observações sobre o desenvolvimento da História Oral na Alemanha e na Europa Centro-Oriental depois do colapso da União Soviética. Uma das principais preocupações é em evidenciar como as populações dessa região lidaram com rupturas nos sistemas ou se envolveram ativamente em fazê-las acontecer - uma vez que nos países da Europa Central e Oriental, na Alemanha, nos Estados do Báltico, na Polônia, na Tchecoslováquia, na Hungria e nos países dos Bálcãs as populações foram obrigadas a assimilar, em apenas três gerações, cinco alternâncias dos sistemas políticos.

Palavras-chave: historiografia; história oral; Alemanha; Europa Centro-Oriental.

The discontinuity of the ruptures of the system and personal reorientation

Abstract: In this article we intend to make some observations on the development of Oral History in Germany and Central and Eastern Europe after the fall of Soviet Union. One of the main concerns is to show how this region's people dealt with ruptures in the political system, or actively made them happen - seen that, in countries of Central and Eastern Europe, Germany, the Baltic and Balkan States, Poland, Czechoslovak, and Hungary, people were forced to assimilate, in only three generations, five alternations in the political system.

Keywords: historiography; oral history; Germany; Central and Eastern Europe. 